\title{
WSPOMAGANIE DECYZJI WYKONAWCY BUDOWLANEGO Z ZASTOSOWANIEM SZTUCZNEJ INTELIGENCJI
}

\begin{abstract}
Odpowiednia selekcja przetargów, do których startuje przedsiębiorstwo budowlane jest ważna w aspekcie kreowania jego pozycji na rynku. By wspomóc procesu myślowy decydenta i zwiększyć skuteczności decyzji opracowuje się modele wspomagające podejmowanie decyzji. W pracy zaproponowano sztuczne sieci neuronowe do budowy modelu wspomagającego decyzje przetargową wykonawcy. Zaproponowany model klasyfikacyjny generuje odpowiedź w formie zalecenia przystąpienia do przetargu bądź rezygnacji z udziału. Model w postaci sieci dwuwarstwowej jednokierunkowej o strukturze MLP 15-2-2 z dwoma neuronami w warstwie ukrytej, osiągnął dobrą jakość działania i prawidłowo sklasyfikował 88,64\% przypadków, a pole pod krzywą ROC (współczynnik AUC) wyniosło 0,92578 .
\end{abstract}

Słowa kluczowe: wspomaganie decyzji przetargowej, sztuczne sieci neuronowe, model klasyfikacyjny, zarządzanie w budownictwie

\section{Wprowadzenie}

W obszarze zarządzania w budownictwie wspomaganie procesów decyzyjnych jest szeroko poruszane w literaturze. Proponowane modele wspomagają decyzje podejmowane przez uczestników procesu budowlanego: zarówno inwestorów [11] jak i wykonawców [7]. Skuteczne podejmowanie decyzji to jedno z największych wyzwań współczesnego budownictwa [6].

Starania o pozyskanie kontraktu budowlanego wymagają od wykonawcy podjęcia kluczowej decyzji, czy ubiegać się o dane przedsięwzięcie i złożyć ofertę przetargową. Odpowiednia selekcja przetargów, do których startuje przedsiębiorstwo jest bardzo ważna w aspekcie budowania pozycji na rynku i wpływa na sukces wykonawcy. Decyzje przetargowe są złożone, dynamiczne i zależne od wielu czynników [15], związanych zarówno z przedsiębiorstwem, jak i przedsięwzięciem, którego dotyczy przetarg.

\footnotetext{
${ }^{1}$ Agnieszka Leśniak, Politechnika Krakowska, Wydział Inżynierii Lądowej, ul. Warszawska 24, 31-155 Kraków, tel.12-6282393, email: alesniak@izwbit.pk.edu.pl
} 
Pierwsze badania dotyczące czynników wpływających na decyzje dotyczące przystąpienia do przetargu przeprowadzono wśród wykonawców robót budowlanych w 1988 roku w USA [1], kolejne w Wielkiej Brytanii [15], potem w innych krajach, w tym także w Polsce [7]. Autorzy tych prac dostrzegają, że czynniki wpływające na decyzje przetargowe w dużej mierze zależą także od otoczenia i rynku, na którym firma funkcjonuje.

Wykonawca podejmując decyzję o udziale w przetargu najczęściej bazuje na doświadczeniu i własnej intuicji. By wspomóc procesu myślowy decydenta, i zwiększyć skuteczności decyzji, opracowuje się modele wspomagające proces podejmowania decyzji. Do budowy tych modeli wykorzystywane są różne narzędzia i metody matematyczne. Większość z nich bazuje na zdefiniowanych czynnikach przetargowych. Spośród istniejących warto wymienić modele z zastosowaniem: metody obwiedni danych [4], regresji logistycznej [3], sztucznych sieci neuronowych [16] i logiki rozmytej [7].

$\mathrm{W}$ artykule zostanie przedstawiona propozycja modelu wspomagającego podjęcie decyzji o udziale w przetargu, wykorzystującego metodę sztucznej inteligencji $\mathrm{w}$ postaci sieci neuronowych. Do modelowania zaproponowano sieci warstwowe jednokierunkowe, które są najczęściej opisywaną i najchętniej wykorzystywaną w zastosowaniach praktycznych architekturą neuronową.

\section{Wybór narzędzia w postaci SSN i budowa bazy danych}

Sztuczne Sieci Neuronowe (skrót SSN) od końca lat pięćdziesiątych uznawane są za jedną z ważniejszych metod badawczych sztucznej inteligencji. Dzięki budowie opartej za wzorcach biologicznych układów nerwowych posiadają niezwykłe właściwości, do których zaliczyć można m.in. [9]:

- szybki proces przetwarzania informacji. Obliczenia w sieciach wykonywane są równolegle. Neurony składające się na sieć wykonują przypadające im zadania obliczeniowe równocześnie,

- zdolność uczenia i uogólniania zdobytej wiedzy. Sieć wytrenowana na wybranej grupie danych uczących potrafi skojarzyć nabyta wiedzę i wykazać dobre działanie na danych nie uczestniczących w procesie uczenia.

W obszarze zarządzania w budownictwie SSN znalazły zastosowanie m.in. w zagadnieniach harmonogramowania przedsięwzięć budowlanych [14] szacowania kosztów robót budowlanych [12] i wspomagania problemów decyzyjnych [5], [2].

Punktem wyjścia do budowy modelu opartego na sztucznej sieci neuronowej były badania czynników przetargowych przeprowadzone w Polsce i prezentowane częściowo w pracy [7]. W ich wyniku wyselekcjonowano 15 czynników wpływających na decyzje o udziale w przetargu w opinii polskich wykonawców: $\mathrm{x}_{1}$ - rodzaj robót, $\mathrm{x}_{2}$ - doświadczenie $\mathrm{w}$ realizacji podobnych przedsięwzięć, $\mathrm{x}_{3}$ - warunki umowne, $\mathrm{x}_{4}$ - reputacja inwestora, $\mathrm{x}_{5}$ - wartość przedsięwzięcia, $\mathrm{x}_{6}$ - potrzeba pracy, $\mathrm{x}_{7}$ - wielkość przedsięwzięcia, $\mathrm{x}_{8}$ - zyski osiągnięte $\mathrm{w}$ prze- 
szłości z podobnych przedsięwzięć, $\mathrm{x}_{9}$ - czas trwania przedsięwzięcia, $\mathrm{x}_{10}$ - kryteria wyboru oferty, $\mathrm{x}_{11}$ - lokalizacja przedsięwzięcia, $\mathrm{x}_{12}$ - czas na przygotowanie oferty, $\mathrm{x}_{13}$ - możliwy udział podwykonawców, $\mathrm{x}_{14}$ - konieczność użycia specjalistycznego sprzętu, $\mathrm{x}_{15}$ - stopień trudności robót.

Kolejnym krokiem podjętym przez autorkę była budowa niezbędnej do modelowania bazy danych. Zidentyfikowane czynniki posłużyły do oceny przedsięwzięć, o które ubiegali się wykonawcy uczestnicząc w przetargach. Ocena każdego czynnika w danym przedsięwzięciu przebiegała w skali od 1 do 7 , gdzie liczby oznaczały: 1 - bardzo mało korzystny (istotny), a 7 - bardzo korzystny (istotny).

Drugim istotnym celem prowadzonych badań było określenie rezultatu dla każdego ocenianego postępowania przetargowego w postaci wyniku:

- W - przetarg wygrany,

- $\mathrm{P}$ - przetarg przegrany.

W badaniach zgromadzono ostatecznie informacje na temat 88 przetargów.

\section{Zdefiniowanie problemu i konstrukcja modelu}

Modelowanie decyzji o udziale w przetargu potraktowano jako zagadnienie klasyfikacji. Jest ona jedną z metod eksploracji danych, której celem jest przypisanie poszczególnych obiektów (przypadków) do odpowiednich predefiniowanych klas, których liczba jest ograniczona. Budowa modelu klasyfikacyjnego, wspomagającego decyzje przetargowe wykonawców sprowadza się do poszukiwania modelu zależności między możliwymi do ustalenia ocenami czynników decydujących o przystąpieniu do przetargu, a zaliczeniem go do odpowiedniego zbioru klasyfikacyjnego: W - wygrana, P - przegrana.

Do rozwiązania zadania klasyfikacyjnego zaproponowano sztuczną sieć neuronową dwuwarstwową, jednokierunkową (MLP - ang. Multi-Layer Perceptron). Warstwę wejściową sieci stanowiło 15, ocenionych dla każdego przypadku przetargu, czynników przetargowych. W warstwie ukrytej przyjmowano różną liczbę neuronów (maksymalnie 20), w zależności od etapu procesu modelowania. Warstwę wyjściową stanowiły 2 neurony reprezentujące klasy:

- W - wygrana - zalecenie wzięcia udziału w przetargu,

- P - przegrana - zalecenie rezygnacji z udziału w przetargu.

Ogólną postać modelu przedstawia rysunek 1. 


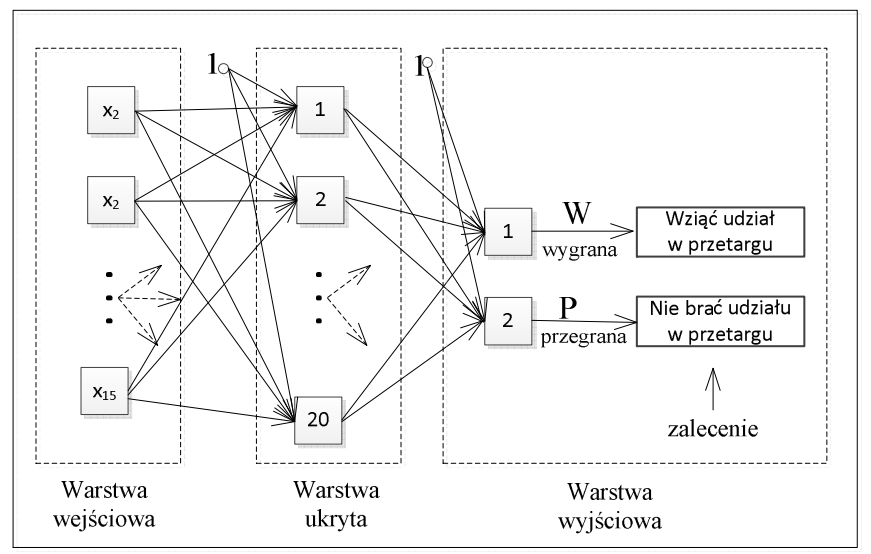

Rys. 1. Schemat zaproponowanego modelu - sieć dwuwarstwowa

Fig. 1. The form of the proposed model - the two layers network

Należy zauważyć, że w pracy [16], po raz pierwszy zaproponowano model wspomagający podejmowanie decyzji o udziale w przetargu $\mathrm{z}$ wykorzystaniem sztucznych sieci neuronowych. Do rozwiązania problemu, zaproponowano sieć neuronową jednokierunkową wielowarstwową, z 18 neuronami w warstwie wejściowej. Wyjście sieci stanowił neuronowy wskaźnik przetargowy - NWP przyjmujący wartości w przedziale $(0,1)$. Wartości $N W P$, co najmniej 0,5 - rekomenduje przystąpienie do przetargu, a poniżej 0,5 - sugeruje rezygnację. W tym miejscu podkreślić należy, dwie zasadnicze różnice pomiędzy istniejącym modelem, a proponowanym przez autorkę:

1) Istniejący model [16] opiera się na bazie danych zawierającej informacje o podjętych przez wykonawców decyzjach w przeszłości (wziął udział w przetargu / nie wziął udziału w przetargu). Zastosowana przez autorkę w niniejszej pracy baza danych zawiera rzeczywiste efekty uczestnictwa w przetargach (wygrana / przegrana).

2) Proponowany przez autorkę model nie jest modelem regresyjnym podającym na wyjściu wskaźnik, którego wielkość należy interpretować w zależności od przyjętej wartości progowej, lecz modelem klasyfikacyjnym, w którym sieć zaleca udział w przetargu poprzez zakwalifikowanie przypadku do klasy $\mathrm{W}$ - wygrana lub sugeruje rezygnację z przetargu, poprzez zakwalifikowanie do klasy P - przegrana.

\subsection{Przebieg procesu modelowania}

Modelowanie przebiegało $\mathrm{w}$ dwóch etapach. W trakcie pierwszego etapu symulacji neuronowych wykorzystano moduł ,automatycznego projektanta sieci” dostępny w programie STATISTICA Automatyczne Sieci Neuronowe. Umożliwia on poszukiwanie sieci - przy różnych funkcjach aktywacji i liczbie neuro- 
nów w warstwie ukrytej. Jako kryterium dopasowania sieci pomiędzy odpowiedziami sieci, a wartościami oczekiwanymi liczono błąd uczenia i testowania sieci w postaci funkcji błędu opartej na sumie kwadratów różnic pomiędzy wartościami zadanymi, a wartościami otrzymanymi (MSE - mean of squares) dla $\mathrm{n}$ próbek:

$$
M S E=\frac{1}{n} \sum_{i=1}^{n}\left(y_{i}-t_{i}\right)^{2}
$$

gdzie:

$n$ - liczba próbek,

$t_{i}$ - wartość rzeczywista i-tej próbki,

$y_{i}$ - wartość i-tej próbki oszacowana przez sieć.

Wynikiem pierwszego etapu był wybór ostatecznej struktury sieci neuronowej MLP. Wybrano sieć MLP 15-8-2. Funkcje aktywacji tej sieci w warstwie ukrytej to funkcja logistyczną, a w warstwie wyjściowej funkcja liniowa. Ta sieć osiągnęła wyniki najbliższe wynikom średnim, uzyskanym przez najlepsze 25 sieci.

W drugim etapie uczenia dla wybranej sieci MLP zmieniano liczbę neuronów w warstwie ukrytej od 2 do 12, zachowując jednocześnie funkcje aktywacji: w warstwie ukrytej - logistyczną, a wyjściowej - liniową.

Dla każdego przypadku stosowano uczenie za wykorzystaniem 10-krotnej walidacji krzyżowej, aby uzyskać wyniki dla sieci, których działanie będzie jak najmniej obarczone sposobem losowania zbiorów.

W sumie wytrenowano 60 sieci. Spośród nich wskazano sieć (Tabela 1), która reprezentuje średnie wartości osiąganych wyników dla rozważanej struktury. Najlepsze wyniki zanotowano w przypadku sieci MLP 15-2-2. Dla tej sieci różnica pomiędzy jakością uczenia dla zbiorów wyniosła $6,81 \%$. Warto zauważyć, że maksymalnie różnica ta wyniosła 11,36\% dla sieci MLP 15-7-2.

Na rysunku 2 przedstawiono osiąganą jakość uczenia sieci w zależności od liczby neuronów w warstwie ukrytej dla zbioru testującego.

Tabela 1. Charakterystyka wybranych sieci MLP

Table 1. Characteristic of selected MLP networks

\begin{tabular}{|c|c|c|c|c|c|c|c|}
\hline \multirow{2}{*}{ L.p. } & $\begin{array}{c}\text { Struktura } \\
\text { sieci }\end{array}$ & $\begin{array}{c}\text { Liczba } \\
\text { ukrytych } \\
\text { neuronów }\end{array}$ & $\begin{array}{c}\text { Zbiór } \\
\text { uczący } \\
{[\%]}\end{array}$ & $\begin{array}{c}\text { Zbiór } \\
\text { testujący } \\
{[\%]}\end{array}$ & $\begin{array}{c}\text { Funkcja } \\
\text { błędu }\end{array}$ & $\begin{array}{c}\text { Aktywacja } \\
\text { ukryte }\end{array}$ & $\begin{array}{c}\text { Aktywacja } \\
\text { wyjściowe }\end{array}$ \\
\hline 1 & MLP 15-2-2 & 2 & $95,45 \%$ & $88,64 \%$ & MSE & Logistyczna & Liniowa \\
\hline 2 & MLP 15-3-2 & 3 & $90,91 \%$ & $85,23 \%$ & MSE & Logistyczna & Liniowa \\
\hline 3 & MLP 15-5-2 & 5 & $90,91 \%$ & $86,36 \%$ & MSE & Logistyczna & Liniowa \\
\hline 4 & MLP 15-7-2 & 7 & $96,59 \%$ & $85,23 \%$ & MSE & Logistyczna & Liniowa \\
\hline 5 & MLP 15-9-2 & 9 & $92,05 \%$ & $84,00 \%$ & MSE & Logistyczna & Liniowa \\
\hline 6 & MLP 15-12-2 & 12 & $93,18 \%$ & $84,09 \%$ & MSE & Logistyczna & Liniowa \\
\hline
\end{tabular}




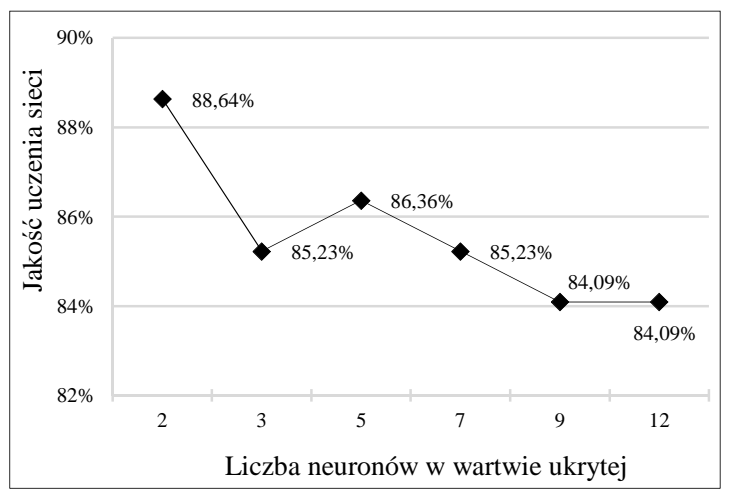

Rys. 2. Jakość uczenia sieci MLP w zależności od liczby neuronów w warstwie ukrytej - wyniki dla zbioru testującego

Fig. 2. The quality of learning MLP network depending on the number of neurons in the hidden layer - the results for the testing set

Analizując powyższy wykres łatwo zaważyć, że najlepsze wyniki uczenia uzyskała sieć 15-2-2. Wzrost liczby neuronów w warstwie ukrytej nie poprawił rezultatów. Najsłabszą jakość uczenia równą 84,09\% osiągnęły sieci z liczbą 9 i 12 neuronów w warstwie ukrytej.

\subsection{Ocena modelu MLP 15-2-2 jako klasyfikatora}

Podsumowanie klasyfikacji dla modelu MLP przedstawiono w tabeli 2. Dane $\mathrm{z}$ tabeli 2 umożliwiają wyznaczenie podstawowych parametrów modelu klasyfikacyjnego. Ich definicje i wzory można znaleźć m.in. w [10]. Wyniki zamieszczono w tabeli 3.

Tabela 2. Podsumowanie klasyfikacji sieci MLP 15-2-2

Table 2. Summary of MLP 15-2-2 network classification

\begin{tabular}{|r|r|c|c|c|}
\hline \multicolumn{2}{|c|}{} & \multicolumn{2}{|c|}{ Rzeczywistość } & \\
\hline \multicolumn{2}{|c|}{ Odpowiedź SSN } & W - wygrana & P - przegrana & Wszystkie \\
\hline \multirow{3}{*}{ MLP 15-2-2 } & W - wygrana & 19 & 5 & 24 \\
\cline { 2 - 5 } & $\mathrm{P}$ - przegrana & 5 & 59 & 64 \\
\cline { 2 - 5 } & Razem & 24 & 64 & 88 \\
\hline
\end{tabular}

Tabela 3. Podstawowe parametry klasyfikatora w postaci sieci neuronowej MLP 15-2-2

Table 3. Basic parameters of the classifier as a neural network MLP 15-2-2

\begin{tabular}{|c|c|c|c|c|c|}
\hline $\begin{array}{c}\text { Model neu- } \\
\text { ronowy }\end{array}$ & Czułość & Swoistość & $\begin{array}{c}\text { Wartość } \\
\text { predykcyjna } \\
\text { dodatnia } \\
\text { MLP 15-2-2 }\end{array}$ & $\begin{array}{c}\text { Wartość } \\
\text { predykcyjna } \\
\text { Ujemna } \\
\text { (NPV) }\end{array}$ & $\begin{array}{c}\text { Skuteczność } \\
\text { (ACC) }\end{array}$ \\
\cline { 2 - 6 } & $79,17 \%$ & $92,19 \%$ & $79,17 \%$ & $92,19 \%$ & $88,64 \%$ \\
\hline
\end{tabular}


Uzyskane wartości są wysokie i wykazują dobre działanie sieci. Analizując je można zauważyć, że sieć lepiej klasyfikuje do klasy P - przegrana (swoistość 92\%), niż do klasy W - wygrana (czułość 79\%). Wybrana sieć sklasyfikowała poprawnie $88,64 \%$ przypadków dla zbioru testującego (skuteczność ACC), popełniając przy tym błąd na poziomie $11 \%$. Pole pod krzywą ROC tzw. współczynnik AUC to wielkość powszechnie traktowana jako miara jakości klasyfikatora [13]. Wielkość pola mieści się w przedziale $(0,1]$. Im jest ono większe tym lepsza jest jakość klasyfikatora. Dla modelu MLP 15-2-2 współczynnik AUC uzyskał wysoką wartość: 0,92578.

Ocena modelu neuronowego w postaci sieci MLP 15-2-2 jako klasyfikatora wypadła zadowalająco.

\section{Podsumowanie}

Uczestnictwo w przetargach ma znaczący wpływ na funkcjonowanie i rozwój przedsiębiorstwa budowlanego. Decyzja o przystąpieniu do przetargu, mimo, że istotna często musi zostać podjęta szybko i w ograniczonym czasie. Wykonawca najczęściej bazuje na doświadczeniu i własnej intuicji. By wspomóc proces decyzyjny i zwiększyć skuteczność podejmowanych decyzji zaproponowano klasyfikacyjny model wspomagający decyzje przetargowe. Został on zbudowany w postaci sztucznej sieci neuronowej. Do modelowania zaproponowano sieć dwuwarstwową jednokierunkową. Najlepszą jakość uczenia osiągnęła sieć z dwoma neuronami w warstwie ukrytej, klasyfikując poprawnie $88,64 \%$ przypadków dla zbioru testującego. Uzyskane wyniki sugerują możliwość wykorzystania modelu w praktyce.

\section{Literatura}

[1] Ahmad I., Minkarah I., Questionnaire survey on bidding in construction, Journal of Management in Engineering, 4, 3, 1988, 229-243.

[2] Anysz H., Foremny A., Kulejewski J., Estimating potential losses of the client in public procurement in case of collusion utilizing a MLP neural networks, Technical Transactions Civil Engineering, 1-B/2014, s. 105-118.

[3] Drew D., Lo H. P., Applying a random coefficients logistic model to contractors' decision to bid, Construction Management and Economics, 25, 2007, s. 387-398.

[4] El-Mashaleh M. S., Decision to bid or not to bid, a data envelopment analysis approach. Canadian Journal of Civil Engineering, 37, 2010, s. 37-44.

[5] Juszczyk M., Leśniak A.: Przegląd możliwości zastosowania sztucznych sieci neuronowych w zarządzaniu kosztami przedsięwzięć budowlanych, Przegląd Naukowy Inżynieria i Kształtowanie Środowiska, 55, 2012, s. 55-64.

[6] Kapliński O., Tupenaite L., Review of the multiple criteria decision making methods, intelligent and biometric systems applied in modern construction economics, Transformation in Business \& Economics, 10, 1, 2011, s. 166-181.

[7] Leśniak A., Plebankiewicz E., Modeling the decision-making process concerning 
participation in construction bidding, Journal of Management in Engineering, 31, 2, 2015, s. 04014032. DOI: 10.1061 / (ASCE)ME.1943-5479.0000237.

[8] Leśniak A., Application of artificial neural networks in indirect cost estimation, International Conference on Numerical Analysis And Applied Mathematics 2013 (ICNAAM-2013), Rhodes, Greece, AIP Publishing, 1558, 2013, s. 1312-1316.

[9] Osowski S., Sieci neuronowe w ujęciu algorytmicznym, WNT, Warszawa 1997.

[10] Panek T., Zwierzchowski J., Statystyczne metody wielowymiarowej analizy porównawczej. Teoria i zastosowania, OW SGH, Warszawa, 2013.

[11] Plebankiewicz E., Model strategii przetargowej wykonawcy budowlanego z zastosowaniem teorii zbiorów rozmytych, praca doktorska, Politechnika Krakowska, Kraków 2001.

[12] Plebankiewicz E., Leśniak A., Overhead costs and profit calculation by polish contractors, Technological and Economic Development of Economy, 19, 1, 2013, s. 141-161.

[13] Sagan A., Krzywe operacyjno-charakterystyczne w ewaluacyjnych badaniach marketingowych, Zeszyty naukowe UE w Krakowie, 864, 2011, s. 5-17.

[14] Schabowicz K., Hoła B., Application of artificial neural networks in predicting earthmoving machinery effectiveness ratios, Archives of Civil and Mechanical Engineering, 8, 4, 2008, s. 73-84.

[15] Shash A.A., Factors considered in tendering decisions by top UK contractors, Construction Management and Economics, 11, 1993, s. 111-118.

[16] Wanous M., Boussabaine H.A., Lewis J., A neural network bid/no bid model: The case for contractors in Syria, Construction Management and Economics, 21, 7 , 2003, s. 737-744.

\section{SUPPORTING CONTRACTORS' DECISION USING ARTIFICIAL INTELLIGENCE}

\section{S u m m a r y}

An appropriate selection of tenders in which the company wishes to participate plays an important part in establishing its position in the market and contributes to the contractor's success. Efficiency of bidding decisions can be improved by applying decision support models. The paper presents a model based on an artificial neural network designed to support contractors' bidding decisions. The network solved the problem of classification. The best network proved to be the MLP 15-2-2 one which generated the most efficient classification, namely the $88,64 \%$ of correctly identified cases that did not participate in the training process. The area under the ROC curve (the coefficient AUC) reached the value 0,92578.

Keywords: supporting bidding decision, artificial neural networks, classification model, construction management

Przestano do redakcji: 07.06.2016 r.

Przyjęto do druku: $30.06 .2016 \mathrm{r}$.

DOI: $10.7862 / \mathrm{rb} .2016 .22$ 